\title{
Effectiveness of 6 Weeks Plyometric Training Protocol on Vertical Jump Ability among High School Amateur Male Volleyball Players-A Randomized Control Trial
}

\section{Chaitanya D Sahasrabudhe ${ }^{1}$, Siddhi Tendulkar ${ }^{2 *}$ and Sucheta Golhar ${ }^{3}$}

${ }^{1}$ Intern, Maharashtra University of Health Sciences, Nashik, India

${ }^{2}$ Assistant Professor of Physiotherapy, Maharashtra University of Health

Sciences, Nashik, India

${ }^{3}$ Professor, Maharashtra University of Health Sciences, Nashik, India

*Corresponding Author: Siddhi Tendulkar, Assistant Professor of Physiotherapy,

Maharashtra University of Health Sciences, Nashik, India.
Received: April 07, 2020

Published: April 28, 2020

(C) All rights are reserved by Siddhi

Tendulkar., et al.

\begin{abstract}
Volleyball is one of the most played games in Indian School going population. Vertical jump height is an essential part in volleyball which can be achieved by strengthening the lower leg musculature. Thus the 6 weeks plyometric training protocol is added to see its results on the strength of lower leg musculature among high school amateur male volleyball players. The subjects ( $\mathrm{n}=40$; age $=$ 10 - 16 years; mean $=12 \pm 1.00$ years) jumping reach Height (mean) $=169.00 \pm 1.00 \mathrm{~cm}$ ) were divided equally into 2 groups called as group A (Experimental) and group B (Control) respectively by simple random sampling method. Group A received the 6 weeks plyometric training protocol and conventional training while group B received only conventional training. Sargent jump test was used to assess the jump heights pre and post at the end of 6 weeks. Unpaired t-test was used to compare the results between the groups. Group A showed significant increase in the difference between the jumping and standing reach heights at the end of 6 weeks (mean difference in the height $=34.25 \mathrm{~cm}$; p-value $<0.05$ ) than in Group B (mean difference in the height $=25.15 \mathrm{~cm}$; p-value $<0.05$ ) at the end of 6 weeks. Also, there is significant improvement in Jumping reach height in Group A (pre = $188.05 \mathrm{~cm} ; \mathrm{post}=203.00 \mathrm{~cm})$ than in Group B (pre = $187.20 \mathrm{~cm}$; post = $195.15 \mathrm{~cm}$ ). Group A showed 43.65\% (mean = $34.25 \mathrm{~cm}$; SD = 7.59) increase while Group $\mathrm{B}$ achieved $31.61 \%$ (mean $=25.15 \mathrm{~cm}$; $\mathrm{SD}=3.73$ ) increase with their initial vertical jump height Both the training protocols are effective in improving vertical jump height but the 6 weeks plyometric training protocol is more effective in improving vertical jump than the conventional training among high school amateur male volleyball players.
\end{abstract}

Keywords: Volleyball; Plyometric Training; Vertical Jump Height; High School Male Volleyball Players

\section{Introduction}

Volleyball is a one of the most played games in Indian school going population. Volleyball is a game which requires explosive power in the lower extremities to jump vertically maximum and deliver the ball in the opponent's court and hence vertical jump is an essential component in volleyball. Vertical jump is commonly performed with a Counter Movement Jump (CMJ), i.e. the jump is performed with the knees flexed at 30 - 60 degrees and then rebounding upwards for a maximal vertical jump [1]. The increase in vertical jump ability following CMJ could be attributed to a combination of the utilization of elastic energy and the stretch reflex potentiation of the muscle activation [2]. The test is performed with one hand on the hip with the other hand raised. Use of arms is allowed to help propel the body upwards, as well as a counter-movement. Greater jump heights can be achieved with this method.

Plyometrics is a rapid pre stretching of a muscle during an eccentric action, followed immediately by a concentric contraction of same muscle and connective tissue. The sequence of events is known as "STRETCH SHORTENING CYCLE" [3]. It is a form of exercise which links strength with speed of movement. According to some evidences plyometric training is an explosive training technique which improves strength and power in musculature.
Vertical jumping is the product of muscular strength and muscular speed. The ability to produce explosive lower body power for a player is an important factor for attaining maximum height of vertical jump. Thus, a specific training technique is required to produce a maximal vertical jump. Thereby a Plyometric Training Protocol is intended to see the changes in the vertical jump ability.

Players were trained for 6 weeks in jumping and landing techniques, jumping for increased vertical height, and increased strength. The training sessions lasted approximately 2 hours a day, 3 days a week, on alternating days (i.e. Monday, Wednesday, and Friday) [4-8]. The program was developed based on a thorough review of the literature and the authors' athletic training experience [4-8].

Since, there is a lack of research available on improving vertical jump among volleyball players, there is a need of doing research which can be helpful in improving vertical jump height among high school volleyball players.

Variety of outcome measures can be used for assessing the vertical jump but the Sargent Jump Test is considered to be an important measuring tool for assessing the vertical jump. Hence in the above study this Sargent Jump Test was used as an Outcome Measure for Vertical Jump Height. 


\section{Materials and Methods}

The informed consent was taken from the players. The 40 amateur male volleyball players were selected based on the inclusion and exclusion criteria from various schools and playing grounds in and around Pune City.

The inclusion criteria was as followed:

- $\quad$ Age: 10 - 16yrs

- High school amateur male volleyball players

- Players who are willing to participate in the study.

The exclusion criteria was as followed:

- Players who have recent fractures of upper and lower limbs (less than 6 months before initiating the protocol) (sportsmed.org).

- Players with any ligament injuries or reconstruction surgeries (less than 6 months before initiating the protocol) (sportsmed.org)

- $\quad$ Female volleyball players [9].

- $\quad$ Players with congenital deformities or specially able players.

They were then asked to perform 3CMJ's. The difference between the jumping and standing reach height was measured and the maximum difference from the 3 CMJ's was used for the further study. The players were trained for 6 weeks on alternate days in a Week and at the end of the 6 weeks again the jumping and standing reach height difference was measured by $3 \mathrm{CMJ}$ 's and the maximum difference from the 3 jumps was considered. They were randomly divided into 2 groups by Simple Random Sampling method. This study was a single-blinded randomized control trial with the randomization done with chit method. The players were blinded during randomization and the study was done.

Group A (Experimental) received the 6-weeks plyometric training protocol and the conventional training protocol while Group B received only the conventional training protocol.

Both the groups received the Conventional Training Protocol which was first demonstrated by the therapist and after properly understanding it the players were asked to perform the training protocol.

The conventional training protocol is as follows.

Conventional training [10]

\begin{tabular}{|l|c|}
\hline \multicolumn{1}{|c|}{ Stretching } & Resistance Training \\
\hline Calf Stretch & Calf Raises \\
\hline Quadriceps Stretch & Leg Extension \\
\hline Hamstring Stretch & Leg Curling \\
\hline IT Band Stretch & Squats \\
\hline Lower Back Stretch & Abdominal Curls \\
\hline Deltoid/Biceps/Pectoral Stretch & Trunk Extension \\
\hline
\end{tabular}

Stretching was performed for 30 seconds for 3 repetitions.

Resistance training was performed with 1 set of each exercise with a set goal of generally 12reps for upper body, 15 reps, for lower body and a range of 15 - 45 reps. for trunk exercises.

Group A (Experimental Group) received both the protocols i.e. plyometric Training and Conventional Training whereas Group B (Control Group) received only The Conventional Training Protocol. Group A received the conventional training followed by the plyometric training. After the conventional training few minutes of rest period is allowed and then the plyometric training is progressed.

The plyometric training protocol will be as follows.

\section{Group A: Experimental group}

The players were train for 6 weeks in jumping and landing techniques., jumping for increased vertical height and increased strength. The training sessions were lasted approximately 2 hours a day, 3 days a week, on alternating days (i.e. Monday, Wednesday and Friday). The program was developed based on a thorough review of literature and the authors' athletic training experience. Three phases will be implemented throughout the jumping program:

1. Phase 1: Technique phase: include initial 2 weeks when proper jumping technique will be demonstrated and drilled. Four basic techniques were stressed: 1] correct posture (spine erect, shoulders back) and body alignment (e.g. Chest over knees) throughout the jump; 2] jumping straight up with no excessive side-to-side or forward-backward movement; 3] soft landing include toe-to-heel rocking and bent knees; 4] instant recoil preparation for next jump. Phrases like "on your toes", "straight as an arrow", "recoil as a spring", etc. were used as verbal and visualization queues for each phase of the jump.

2. Phase 2: Fundamental phase: was concentrated on the use of proper jumping technique to build a base of strength, power and ability.

3. Phase 3: Performance phase: was focused on achieving maximal vertical jump height.

Throughout each session of the first two phases, exercise was increased by duration. Each player was encouraged to do as many jumps as possible using proper technique. As players got fatigue, they were asked to stop if they are not able to execute the jumps correctly. During phase 3 players were concentrated on the height achieved in each jump. 30 seconds of recovery time was allotted to the players between each exercise.

Jumping exercise included are:

1. 180 degree jumps: Two footed jump. Rotate 180 degree in the air. Hold landing 2 seconds, the repeat in reverse direction.

2. Bounding for distance: Start bounding in place and slowly increase distance with each step, keeping knees high. 
3. Bounding in place: Jump from one leg to the other straight up and down, progressively increasing rhythm and height.

4. Broad-jumps-stick (hold) landing: Two footed jump as far as possible. Hold landing for 5 seconds.

5. Cone jumps: Double leg jump with feet together, jump side-toside over cones quickly. Repeat forward and backward.

6. Hop, hop stick: Single legged hop. Stick second landing for 5 seconds. Increase distance of hop as technique improves.

7. Jump into bounding*: Two footed broad jump. Land on single leg, then progress into bounding for distance.

8. Jump, jump, jump, vertical: Three broad jumps with vertical jump immediately after landing the third broad jump.

9. Mattress jumps: Two footed jumps on mattress, tramp, or other easily compressed devices. Perform side-to-side and front-to-back.
10. Scissors jump: Start in stride position with one foot well in front of the other. Jump up, alternating foot positions in midair.

11. Single legged jumps distance*: One legged hop for distance. Hold landing (knees bent) for 5 seconds.

12. Squat jumps*: Standing jump raising both arms overhead, land in squatting position touching both hands to floor.

13. Step, jump up, down, vertical: Two footed jump onto 6 - 8 inch step. Jump of step with two feet, then vertical jump.

14. Tuck jumps: From standing position jump and bring both knees up to chest as high as possible. Repeat quickly.

15. Wall jump (ankle bounces): With knees slightly bent and arms raised overhead, bounce up and down off toes.

*These jumps performed on mats.

Plyometric training protocol $[10]$

\begin{tabular}{|c|c|c|}
\hline Exercise & Repetitions or Time & Repetitions or Time \\
\hline Phase 1: Technique & Week 1 & Week 2 \\
\hline Wall Jumps & 20 Seconds & 25 Seconds \\
\hline Tuck Jumps & 20 Seconds & 10 Repetitions \\
\hline Broad Jumps Stick Land & 5 Repetitions & 15 Seconds \\
\hline Squat Jumps & 10 Seconds & 30sec/30sec (Side to Side, Back-Front) \\
\hline Double Leg Cone Jumps & 30sec/30sec (Side to Side, Back-Front) & 25 Seconds \\
\hline 180 Degree Jumps & 20 Sec & 25 Seconds \\
\hline Bounding in Place & $20 \mathrm{Sec}$ & \\
\hline
\end{tabular}

\begin{tabular}{|c|c|c|}
\hline Phase 2: Fundamental & Week 3 & Week 4 \\
\hline Wall Jumps & 30 Seconds & 30 Seconds \\
\hline Tuck Jumps (B) & 30 Seconds & 8 Repetitions \\
\hline Jump, Jump, Jump. Vertical Jump & 5 Repetitions & 20 Seconds \\
\hline Squat Jumps & 20 Seconds & 30sec/30sec (Side to Side, Back-Front) \\
\hline Bounding for Distance & 1 Run & 30 Seconds \\
\hline Double Leg Cone Jumps & 30sec/30sec (Side to Side, Back-Front) & 5 Repetitions/Leg \\
\hline Scissor Jumps & 30 Seconds & 5 Repetitions/Leg \\
\hline Hop, Hop, Stick & &
\end{tabular}

\begin{tabular}{|c|c|c|}
\hline Phase 3: Performance & Week 5 & Week 6 \\
\hline Wall Jumps & 30 Seconds & 10 Repetitions \\
\hline Step, Jump Up, Down, Vertical & 5 Repetitions & 5 Repetitions/Leg \\
\hline Mattress Jumps & 30sec/30sec (Side to Side, Back-Front) & 25 Seconds \\
\hline Single Legged Jumps Distance & 5 Repetitions/Leg & 4 Runs \\
\hline Squat Jumps & 25 Seconds & 5 Repetitions/Leg \\
\hline Jump into Bounding & 3 Runs \\
\hline
\end{tabular}

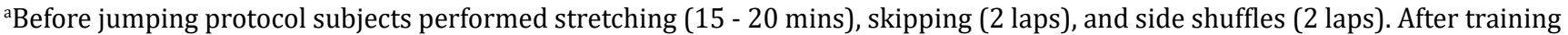
subjects were cool down (walk for 2 mins), stretching ( 5 mins). Each jump exercise was followed a 30 seconds rest period.

'These jumps performed on mats. 
Group B: Control group

The subjects with even numbers are placed into Group B.

They received Conventional training protocol.

Conventional training

\begin{tabular}{|c|c|}
\hline Stretching & Resistance Training \\
\hline Calf Stretch & Calf Raises \\
\hline Quadriceps Stretch & Leg Extension \\
\hline Hamstring Stretch & Leg Curling \\
\hline IT Band Stretch & Squats \\
\hline Lower Back Stretch & Abdominal Curls \\
\hline Deltoid/Biceps/Pectoral Stretch & Trunk Extension \\
\hline
\end{tabular}

Stretching was performed for 30 seconds for 3 repetitions.

Resistance training was performed with 1 set of each exercise with a set goal of generally 12 reps for upper body, 15 reps. For lower body and a range of 15 - 45 reps. for trunk exercises.

\section{Outcome measures}

Sargent jump test (Reliability $=0.96$ ) [11] will be utilized to assess the pre and post values in each group:

- In this jump-and-reach test, the jumping height was determined by subtracting standing reach height from jumping reach height. The test was performed from countermovement with the arm swing.

- The test should be performed pre and post of training programs for 3 times. The maximum jumping height distance can be taken for further evaluation (Reliability $=0.96$ ) [11].

\section{Statistical analysis}

The data has passed the normality tests. Thus, the data followed a normal distribution curve. Hence parametric tests were performed on the above data for the analysis. For the comparison between the groups unpaired t-test was used and for comparison within the group paired t-test was used.
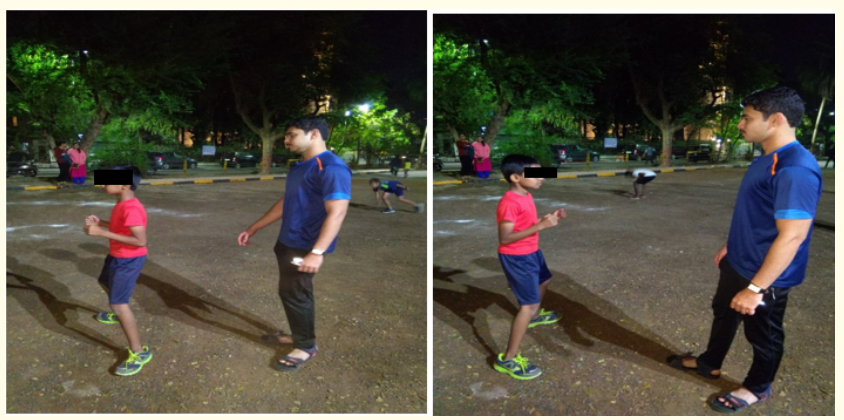

Figure A: 180 degree jumps.

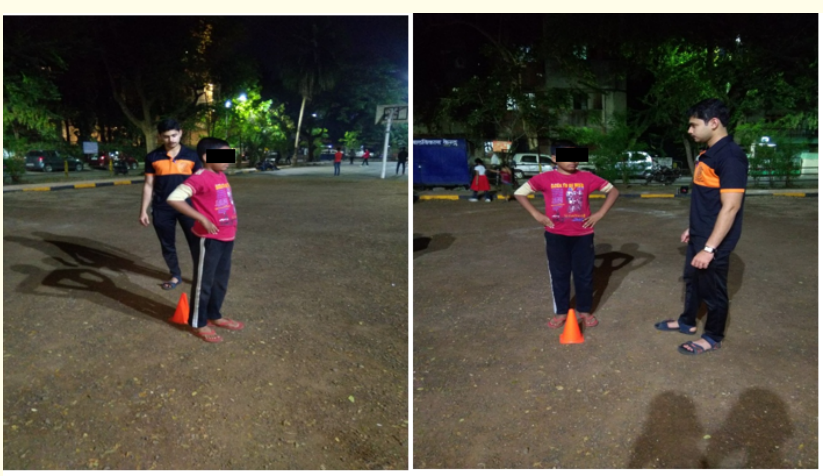

Figure B: Cone jumps.
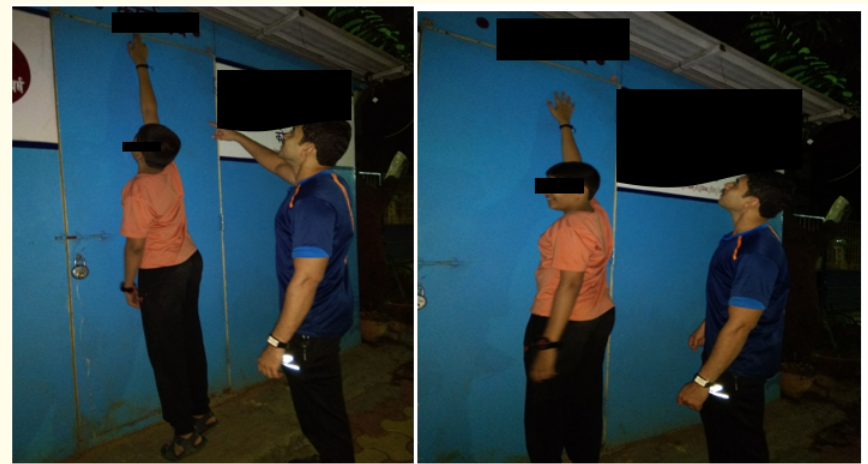

Figure C: Wall jumps.

Results

\begin{tabular}{|c|c|c|c|}
\hline \multirow{2}{*}{$\begin{array}{c}\text { Age } \\
\text { group }\end{array}$} & \multicolumn{2}{|c|}{ Group } & \multirow{2}{*}{ Total } \\
\cline { 2 - 3 } & Group A & Group B & \\
\hline $10-12$ & 9 & 10 & 19 \\
\hline $13-14$ & 9 & 9 & 18 \\
\hline$>14$ & 2 & 1 & 3 \\
\hline Total & 20 & 20 & 40 \\
\hline
\end{tabular}

Table 1: Shows the age wise distribution of the subjects among the two groups.

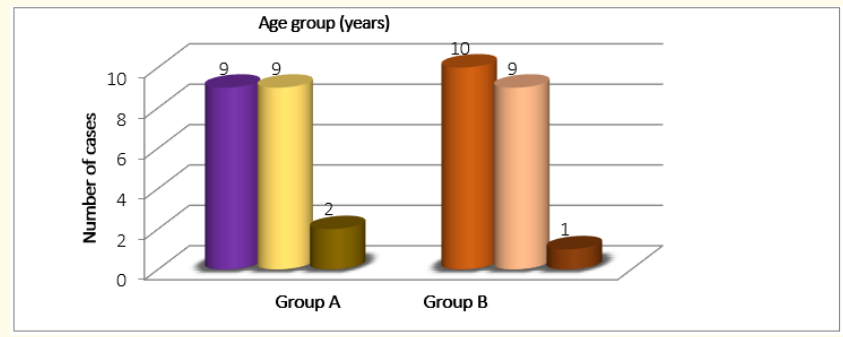

Figure 1: Shows the age wise distribution of the subjects.

\begin{tabular}{|c|c|c|c|c|}
\hline \multirow{2}{*}{ Group } & \multirow{2}{*}{$\begin{array}{c}\text { Number of } \\
\text { patients }\end{array}$} & \multicolumn{2}{|c|}{ Age } & \multirow{2}{*}{ p-value } \\
\cline { 3 - 4 } & & Mean & SD & \\
\hline Group A & 20 & 12.85 & 1.31 & \multirow{2}{*}{0.904} \\
\hline Group B & 20 & 12.90 & 1.29 & \\
\hline
\end{tabular}

Table 2: Shows the mean ages of the subjects among the two groups.

p-value $>0.05$ (Not Significant) Unpaired t-test used. 


\begin{tabular}{|l|c|c|c|c|}
\hline \multirow{2}{*}{ Group } & \multirow{2}{*}{$\begin{array}{c}\text { Number of } \\
\text { patients }\end{array}$} & \multicolumn{2}{|c|}{ Standing Height } & \multirow{2}{*}{ p-value } \\
\cline { 3 - 4 } & 20 & Mean & SD & \\
\hline Group A & 208.75 & 3.80 & 0.270 \\
\hline Group B & 20 & 170.0 & 3.24 & \\
\hline
\end{tabular}

Table 3: Shows the mean standing reach height among the two groups.

p-value > 0.05 (Not Significant) Unpaired t-test used.

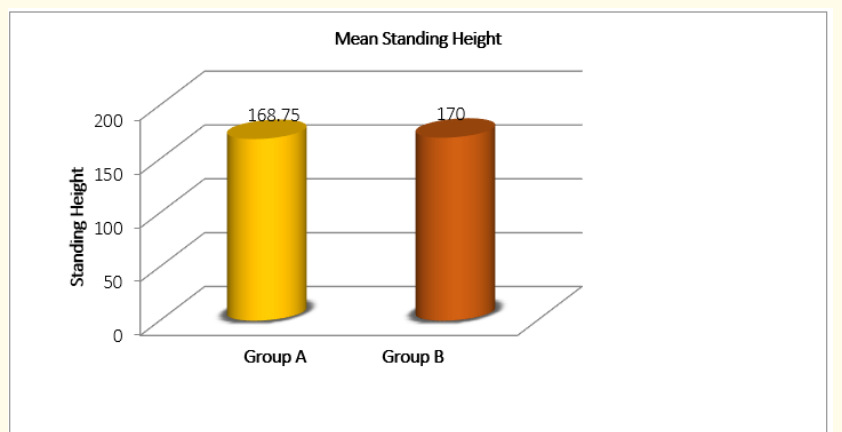

Figure 2: Shows the mean standing height between group A and group B.

\begin{tabular}{|l|c|c|c|c|c|c|}
\hline \multirow{2}{*}{ Group } & \multirow{2}{*}{$\begin{array}{c}\text { Number } \\
\text { of } \\
\text { patients }\end{array}$} & \multicolumn{2}{|c|}{$\begin{array}{l}\text { Difference between Jumping } \\
\text { Height and Standing Height }\end{array}$} & \multirow{2}{*}{$\begin{array}{c}\text { p-value } \\
\text { (Intra } \\
\text { group) }\end{array}$} \\
\cline { 3 - 6 } & & Mean & SD & Mean & SD & \\
\hline Group A & 20 & 19.30 & 5.58 & 34.25 & 7.59 & $<0.001 \#$ \\
\hline Group B & 20 & 17.20 & 5.35 & 25.15 & 3.73 & $<0.001 \#$ \\
\hline $\begin{array}{l}\text { p-value } \\
\text { (inter } \\
\text { group) }\end{array}$ & & \multicolumn{2}{|c|}{0.232} & \multicolumn{2}{|c|}{$<0.001^{*}$} & \\
\hline
\end{tabular}

Table 4: Shows the differences between the Jumping and Standing reach heights between Group A and Group B. *Significant ( $p$-value < 0.05) Unpaired t-test used. \# Significant (p-value $<0.05$ ) Paired t-test used.

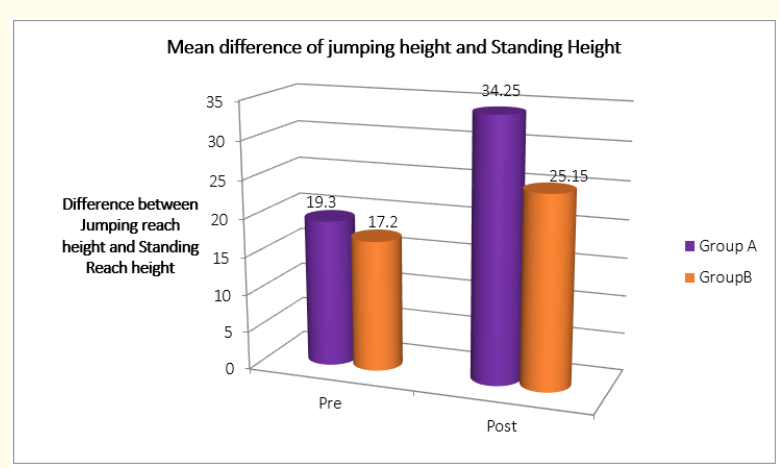

Figure 3: Shows the differences between standing and jumping reach heights between group A and group B.

\begin{tabular}{|c|c|c|}
\hline & Pre Jumping Height & Post Jumping Height \\
\hline $\begin{array}{c}\text { Experimental } \\
\text { Group }\end{array}$ & 188.05 & 203.00 \\
\hline
\end{tabular}

Table 5: Shows the Pre and Post Jumping Reach Heights in Group A.

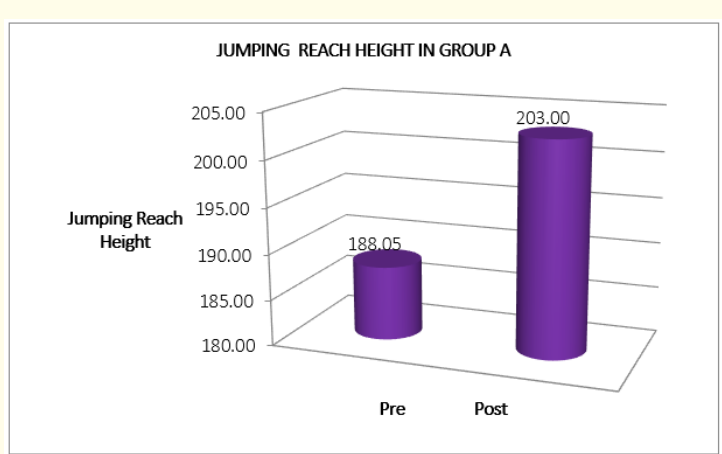

Figure 4: Shows the pre and post value of jumping reach height in group $A$.

\begin{tabular}{|c|c|c|}
\hline & Pre Jumping Height & Post Jumping Height \\
\hline $\begin{array}{c}\text { Conventional } \\
\text { group }\end{array}$ & 187.20 & 195.15 \\
\hline
\end{tabular}

Table 6: Shows the Pre and Post value of Jumping Reach Height in Group B.

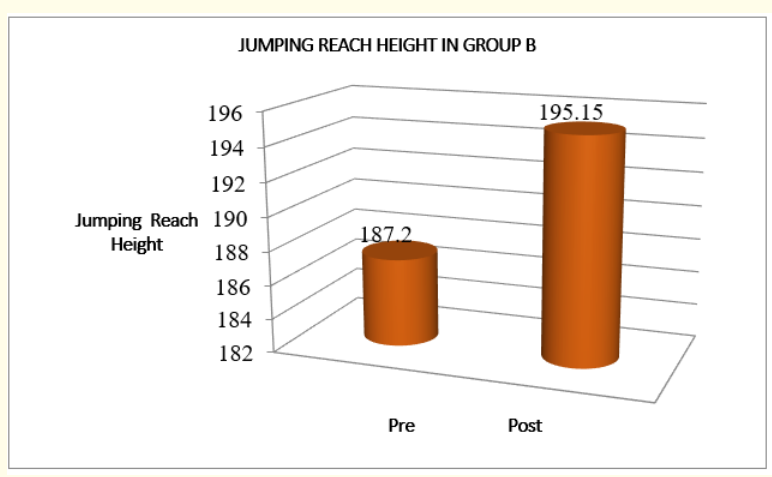

Figure 5: Shows the pre and post value of jumping reach height in group $B$.

\begin{tabular}{|l|c|c|}
\hline & Experimental group & Control Group \\
\hline Post Jumping Height & 203.00 & 195.15 \\
\hline
\end{tabular}

Table 7: Shows the post jumping height in Group A and Group B.

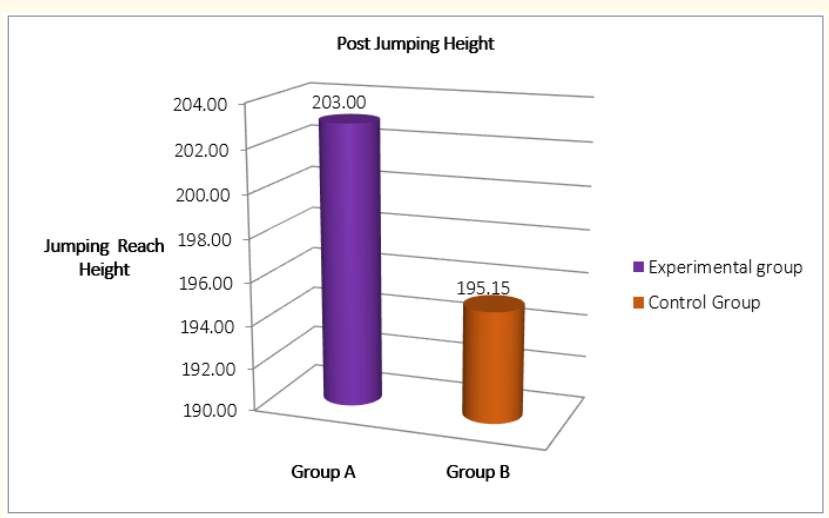

Figure 6: Shows the post jumping height in group A and group B. 


\section{Discussion}

The 6-weeks plyometric training protocol on vertical jump height among amateur male volleyball players was done on 40 amateur male volleyball players.

The subjects were divided into two groups by simple random sampling. Group A called 'Experimental' incorporated into the plyometric training protocol and conventional protocol while the Group B called 'Control' participated into only conventional protocol.

Table 1 showed that there were 19 subjects from age group = 10 - 12yrs.; 18 subjects from 12 - 14yrs; 3 subjects from age group $>14$ yrs.

Table 2 has the mean ages for Group A (12.85 yrs) and Group B (12.90 yrs) which depicted there is no significant variation in the age between the 2 groups which standardized the data and there were no drop outs in the study so the result calculated is for 40 subjects.

Figure 3 depicted the difference in mean jumping heights from both the groups. The pre difference in Group A was $19.30 \mathrm{~cm}$ which was increased to $34.25 \mathrm{~cm}$ post the training, on the other hand the pre difference in Group B was $17.20 \mathrm{~cm}$ which was increased to $25.15 \mathrm{~cm}$ at the end of 6 weeks of training session.

The experimental group (Group A): Mean jumping height: pre = $188.05 \mathrm{~cm}$; post $=203.00 \mathrm{~cm}$, The control group (Group B): Mean jumping height: pre $=187.20 \mathrm{~cm}$; post $=195.15 \mathrm{~cm}$ which suggested that there was more significant increase in jumping height in the experimental group than control group.

Figure 4 showed the pre and post jumping reach heights in Experimental Group (Group A) (pre $=188.05 \mathrm{~cm}$; post $=203.00$ ) while figure 5 showed that the pre and post jumping reach heights in Control Group (Group B) (pre = 187.20; post $=195.15$ ) which depicted that group $A$ has more increase in post jumping reach height than group B. Group A showed 43.65\% (mean $=34.25 \mathrm{~cm}$; $\mathrm{SD}=7.59$ ) increase while Group B achieved 31.61\% (mean $=25.15$ $\mathrm{cm} ; \mathrm{SD}=3.73$ ) increase with their initial vertical jump height. Figure 6 also showed that the post Jumping Reach Height in Group A is more as compared to post Jumping Reach Height in Group B.

Holcomb., et al. showed that during a plyometric movement the muscles undergo a very rapid switch from eccentric phase to the concentric phase. This Stretch-Shortening Cycle decreases the time of the amortization phase that in turn allows greater than normal power production $[12,13]$. The muscles' stored elastic energy and stretch reflex response are essentially exploited, permitting more work to be done by the muscles during the concentric phase of the movement $[12,14]$.

Potteiger., et al. showed that there is significant increase in Type I and Type II muscle fibers which improved muscle force production along with increase in the muscle fibre size $[15,16]$
According to the available literature neuromuscular adaptations such as increased inhibition of antagonists muscles as well as better activation and co-contraction of synergistic muscles may account for improvement in power output hence increasing the vertical jump performance which justifies the objective of the study $[17,18]$.

\section{Conclusion}

Hence from the above study it can be concluded that both the training protocols are effective on improving the vertical jump height but the 6-weeks plyometric training protocol is more effective over the conventional protocol on improving the vertical jump ability among high school amateur male volleyball players.

\section{Bibliography}

1. Gehri Daniel J., et al. "A Comparison of Plyometric Training Techniques for Improving Vertical Jump Ability and Energy Production". The Journal of Strength and Conditioning Research (1998): 85-89.

2. Bosco Carmelo and Paavo V Komi. "Potentiation of the Mechanical Behavior of the Human Skeletal Muscle through Prestretching". Acta Physiologica Scandinavica 106.4 (1979): 467472.

3. Miller Michael G., et al. "The Effects of a 6-Week Plyometric Training Program on Agility". Journal of Sports Science and Medicine 5.3 (2006): 459-465.

4. Bobbert Maarten F. "Drop Jumping as a Training Method for Jumping Ability". Sports Medicine 9.1 (1990): 7-22.

5. Dunnam Laura 0., et al. "Comprehensive Evaluation of the University of Alabama at Birmingham Women"s Volleyball Training Program". National Strength and Conditioning Association Journal 10.1 (1988): 50-52.

6. Marsit Joseph L and William J Kraemer. "Program Design: Beginning off-Season Workout for High School Volleyball". National Strength and Conditioning Association Journal (1992).

7. McGown CM., et al. "Gold Medal Volleyball: The Training Program and Physiological Profile of the 1984 Olympic Champions". Research Quarterly for Exercise and Sport 61.2 (1990): 196-200.

8. Pestolesi TJ. "Selected Training Programs to Improve Vertical Jump in High School Athletes". Master"s Thesis TJ State University, Long Beach, California (1989).

9. Wodarska M., et al. "Menstrual Cycle Disorders in Female Volleyball Players". Journal of Obstetrics and Gynaecology: The Journal of the Institute of Obstetrics and Gynaecology 33.5 (2013): 484-488.

10. Hewett Timothy E., et al. "Plyometric Training in Female Athletes". The American Journal of Sports Medicine 2.6 (1996): 765-773. 
11. Markovic Goran., et al. "Reliability and Factorial Validity of Squat and Countermovement Jump Tests". Journal of Strength and Conditioning Research 18.3 (2004): 551-555.

12. Holcomb William., et al. "The Effectiveness of a Modified Plyometric Program on Power and the Vertical Jump". Journal of Strength and Conditioning Research 10.2 (1996): 89-92.

13. Potteiger Jeffrey A., et al. "Muscle Power and Fiber Characteristics Following 8 Weeks of Plyometric Training". Journal of Strength and Conditioning Research (1999).

14. Hedrick Allen and Jason C Anderson. "The Vertical Jump: A Review of the Literature and a Team Case Study". Strength and Conditioning Journal 18 (1996): 7-12.

15. Gollnick PD., et al. "Muscular Enlargement and Number of Fibers in Skeletal Muscles of Rats". Journal of Applied Physiology Respiratory Environmental and Exercise Physiology (1981).

16. Thorstensson Alf., et al. "Effect of Strength Training on Enzyme Activities and Fibre Characteristics in Human Skeletal Muscle". Acta Physiologica Scandinavica 96.3 (1976): 392-398.

17. Komi Paavo V. "Physiological and Biomechanical Correlates of Muscle Function: Effects of Muscle Structure and Stretchshortening Cycle on Force and Speed". Exercise and Sport Sciences Reviews (1984): 81-121.

18. Lyttle Andrew D., et al. "Enhancing Performance: Maximal Power Versus Combined Weights and Plyometrics Training". Journal of Strength and Conditioning Research (1996).

\section{Assets from publication with us}

- Prompt Acknowledgement after receiving the article

- Thorough Double blinded peer review

- Rapid Publication

- Issue of Publication Certificate

- High visibility of your Published work

Website: https://www.actascientific.com/

Submit Article: https://www.actascientific.com/submission.php Email us: editor@actascientific.com

Contact us: +919182824667 